\title{
Analysis of Evaluated Sentiments; a Pseudo-Linguistic Approach and Online Acceptability Index for Decision-Making with Data: Nigerian Election in View
}

\author{
Okpala Izunna Udebuana ", Ijioma Patricia Ngozi, Emejulu Augustine Obiajulu \\ Department of Communication and Translation Studies, National Institute for Nigerian Languages, Aba, Nigeria \\ Email address: \\ izunna.okpala@yahoo.com (O. I. Udebuana),ngolemmy@yahoo.com (I. P. Ngozi),omejulus@yahoo.com (E. A. Obiajulu) \\ ${ }^{*}$ Corresponding author
}

To cite this article:

Okpala Izunna Udebuana, Ijioma Patricia Ngozi, Emejulu Augustine Obiajulu. Analysis of Evaluated Sentiments; a Pseudo-Linguistic Approach and Online Acceptability Index for Decision-Making with Data: Nigerian Election in View. Internet of Things and Cloud Computing. Vol. 7, No. 2, 2019, pp. 39-44. doi: 10.11648/j.iotcc.20190702.11

Received: August 9, 2019; Accepted: August 24, 2019; Published: September 9, 2019

\begin{abstract}
Sentiments measured properly always give direction to future occurrences. Without an expression through feelings plus sensitive statements, it would be difficult to predict future occurrence. But when feelings are expressed through spoken languages or written texts, a projection of future event can be evaluated to an extent. Nigeria is blessed with intellectuals and over $48 \%$ of the population are actively involved in social media. The beauty of this great nation is in its diversity and practice of democracy. Since independence, they have experienced variations in handling their hard-earned democracy. The goal of this paper is to compare analyzed sentiments from the Nigerian people across the 6 geopolitical zones and the aftermath of the Nigerian election in 2019. Data is retrieved from the social media using python programming language across 2 major platforms twitter and Facebook. A word cloud is introduced later to differentiate various sentiments using a spiral loop to map the various artifacts into corpora. Vader machine learning system called Sentiment Intensity Analyzer was used to the analyze each statement to retrieve positive and negative sentiments. This study employs two methodologies, quantitative and qualitative methods with significant levels of descriptive approach in data analysis. The researchers explore the results of the analysis to verify whether significant decisions can be made in the future from data generated from social media, using the 2019 Nigerian election as a case study. A dashboard was developed to plot the different feelings and how they influenced the general election outcome. PHP and JavaScript were used to achieve this. It is recommended that stakeholders in the 'digital humanities and arts' explore the findings in this paper especially if the result comes at least close to $80 \%$ of the real result.
\end{abstract}

Keywords: Sentiment Analysis, Social Media, Machine Learning, Prediction, Nigerian Election

\section{Introduction}

Mining large body of collective thoughts can prove to be one potentially powerful method of gauging public sentiment on any number of topical areas. Languages play major role in information transfer and thus, central to exchange of information amongst individuals, groups and the global population [1]. The 2019 general election in Nigeria differs from the previous elections in the Fourth Republic (1999date). According to an online database provided by Election Guide (Democracy Assistance and Election views), the average voters' turnout was $51.8 \%$, which was considerably lower than the turnout in the previous election held in 2015. An article titled "Data: Nigeria's Presidential election records lowest voter Turnout in 20 Years" by Sahara reporters tries to corroborate the information in a more detailed fashion. They likened the situation to have been caused by initial cancellation of the 2019 polls earlier scheduled for February 16, 2019, with an eventual rescheduling for February 23, 2019 [2]. However, Yiaga Africa differed on their explanation to the cause as they attributed the low turnout to be caused by the growing sense of disconnect between the Nigerian people and the political elite [3].

The existence of myriad social networking services and 
other forms of web-based outlets in recent years gives opportunity to anyone who has access to the internet to contribute their thoughts and opinions to a potentially worldwide audience. Specifically, the twitter platform has become a common and accessible venue for people to post information on a wide variety of topics, and as such, social media platforms can be thought of as a large cross-section of mass opinion on a myriad of topics, but the fact that largely anyone can post their opinions online has both advantages and disadvantages; on the positive side, it serves as a widely accessible outlet for publishing one's thoughts and ideas. On the negative side, however, the reality that any author can host a blog or open a social media account increases the question of credibility, one can comfortably claim that in many cases, not all writers should be deemed similarly reliable; with regard to a specified topic, some writers should be regarded as more authentic than others.

\section{Methodology}

This research uses two methodologies, quantitative and qualitative approach with a significant level of descriptive approach in data analysis. The authors explore the result from the analysis to check if meaningful decision can be taken from data produced from the social media in the future using 2019 Nigerian election as a case study. The researchers analyse the intangible and inexact concerns that belong to the social and experiential base. This approach checks the kind of intelligence that machines exhibit, since things like positive associations with a brand, conflict resolution, management trustworthiness, customer satisfaction, competitive advantage and cultural shifts are associated with human sentiments.

\section{Theoretical Framework}

The field of data analytics and machine learning has grown exponentially in terms of solving human problems. With the explosion of Web 2.0 platforms such as blogs, discussion forums, peer-to-peer networks, and various other types of social media plus automated behavioural systems introduced by web 5.0 and 6.0 , organizations have at their disposal an unprecedented reach and power by which they get feedbacks on customer experiences and opinions, positive or negative, regarding any product or service they offer. Social media has been playing an increasing role and has become an important alternative information channel to traditional media like local newspapers and television channels. Individuals and communities have used social media for many tasks, from warning others of unsafe areas, for fund raising and opinion pools [4]. Sentiment analysis and text mining have recently enjoyed increasing interest in the research circle, but there has been a steady undercurrent of interest for quite a while. Early projects on beliefs can act as a guide, though computer systems were not used to quantify or measure belief as illustrated by Carbonell [5] or the paper written by Wilks [6] on "point of views". Recent works focused mostly on interpretation of metaphor, narrative, emotions, linguistic notions evident in a text for machine learning and corpus development [7]. This study aims at applying sentiment analysis in a big data environment using social media primarily geared towards growth or prediction. The amount of data that flows every second on the media can be harnessed to solve various problems plaguing an organization. Just as gold is mined, information can be mined as well. Sentiments expressed in social media are one of the techniques for detecting the variables that grow a business [4]. In particular, it is useful to better understand the dynamics of the network including users' feelings, panics, and concerns as it is used to identify the polarity of sentiments expressed by users during economic booms to improve decision making. It can help managers find answers to their questions, thereby influencing better decisions regarding an event without pay, as the case with traditional public surveys. Using the results obtained from sentiment analysis, managers can figure out where they should look for particular information regarding recent happenings and company trends. Mark Zuckerberg the founder of Facebook, had the mind-set of growth while growing Facebook. Companies that have successfully used analytics usually have a viral loop naturally built into the on-boarding process. Sentiments analysis can thus be used to forecast long-term success.

\section{Data Analysis}

Data is crucial in any academic research. This research made use of information from Twitter between February and March 2019. The Streaming API contains public statuses from all users, filtered in various ways: By userid, by keyword, by random sampling, by geographic location, etc.

\subsection{Twitter API in a Nutshell}

Twitter offers several API, or methods we can use to retrieve tweets.

a) Streaming API.

b) Search API.

In this study, we used the streaming API primarily to stream all status. This was achieved by connecting the "statuses" endpoint. Secondly we also made use of the tweepy an opensource library which provides access to the Twitter API for Python. Other libraries like python-twitter provide many functions too, but the tweepy has most active forum and most commits to the code in the last few years. To be able to get access to tweets, credentials needs to be created.

\subsection{Setting up the Connection Using the Tweepy API Features}

Tweepy provides useful parameters for handling download restrictions from Twitter API:

a) OAuthHandler: stores the credentials such as access_token, access_token_secret, consumer_key, consumer_secret developer.twitter.com. 
b) API class: sets the connection to Twitter API using your credentials from OAuthHandler.

Consumer

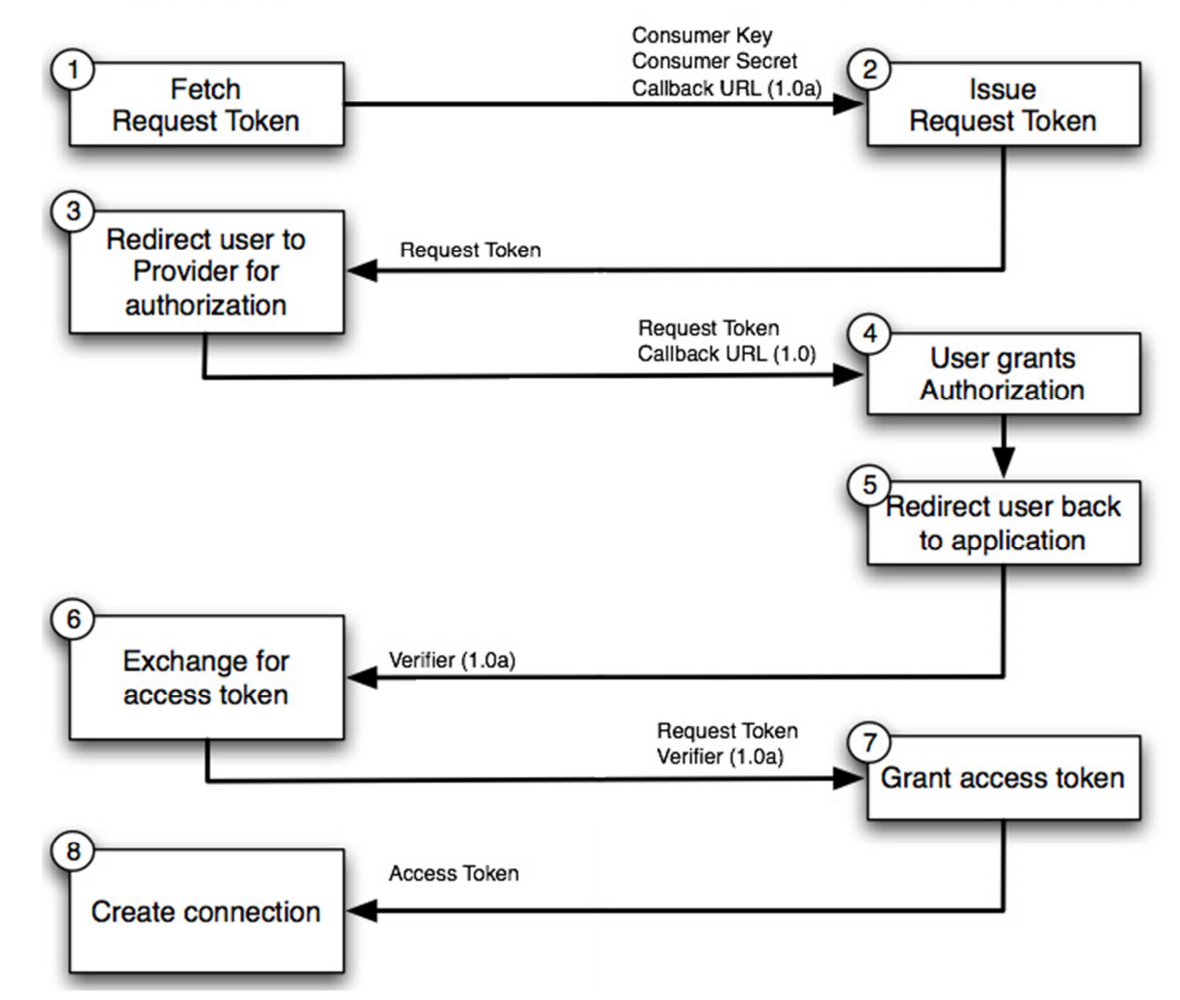

\section{Service Provider}

Figure 1. Twitter connectivity and tokenization.

c) Stream class: streams the downloaded data into JSON file.

b) On_error handles errors returned by the API.

c) Popular hashtags used for tracking: \#NigeriaDecides, \#NigeriaDecides2019, \#NgLeaks, \#buhari, \#atiku, \#kingsleymoghalu, \#feladurotoye, \#omoyelesowore, \#pmb, \#osinbanjo, \#peterobi, \#AtikuInKano, \#PMBInKano, \#Nigerianelection, \#Nigeriandecides.

a) On_data is the method that will be called when a tweet is downloaded. We then print the data.

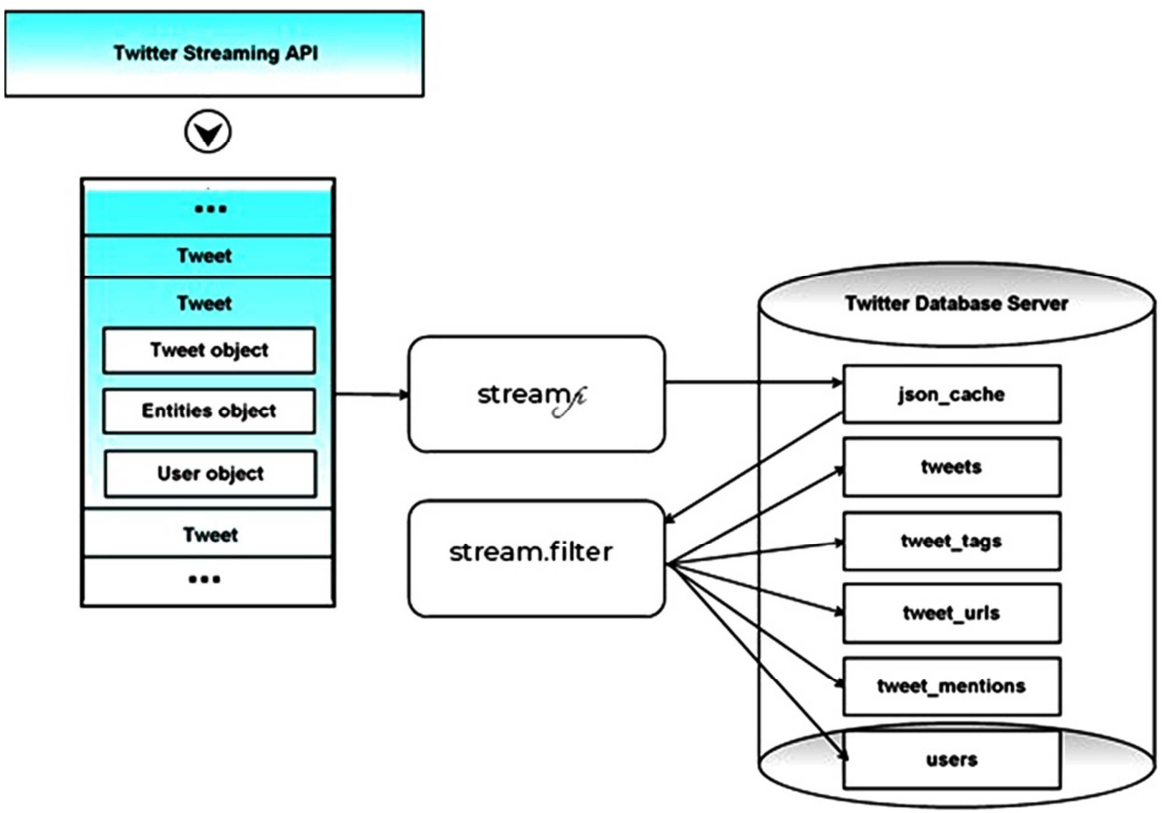

Figure 2. Data streaming diagram. 


\subsection{Sentiment Analysis}

For the sentiment analysis, we chose a sentiment analyser called VADER (Valence Aware Dictionary for Sentiment Reasoning), which is available in Python's NLTK library. VADER was intended to analyse live channels of social media content. The tool developers also evaluated it on "sentence-level snippets" from NYT opinion chunks [8]. VADER interfaces with a lexicon called Senti Word Net, which is an extension of the lexical database WordNet.

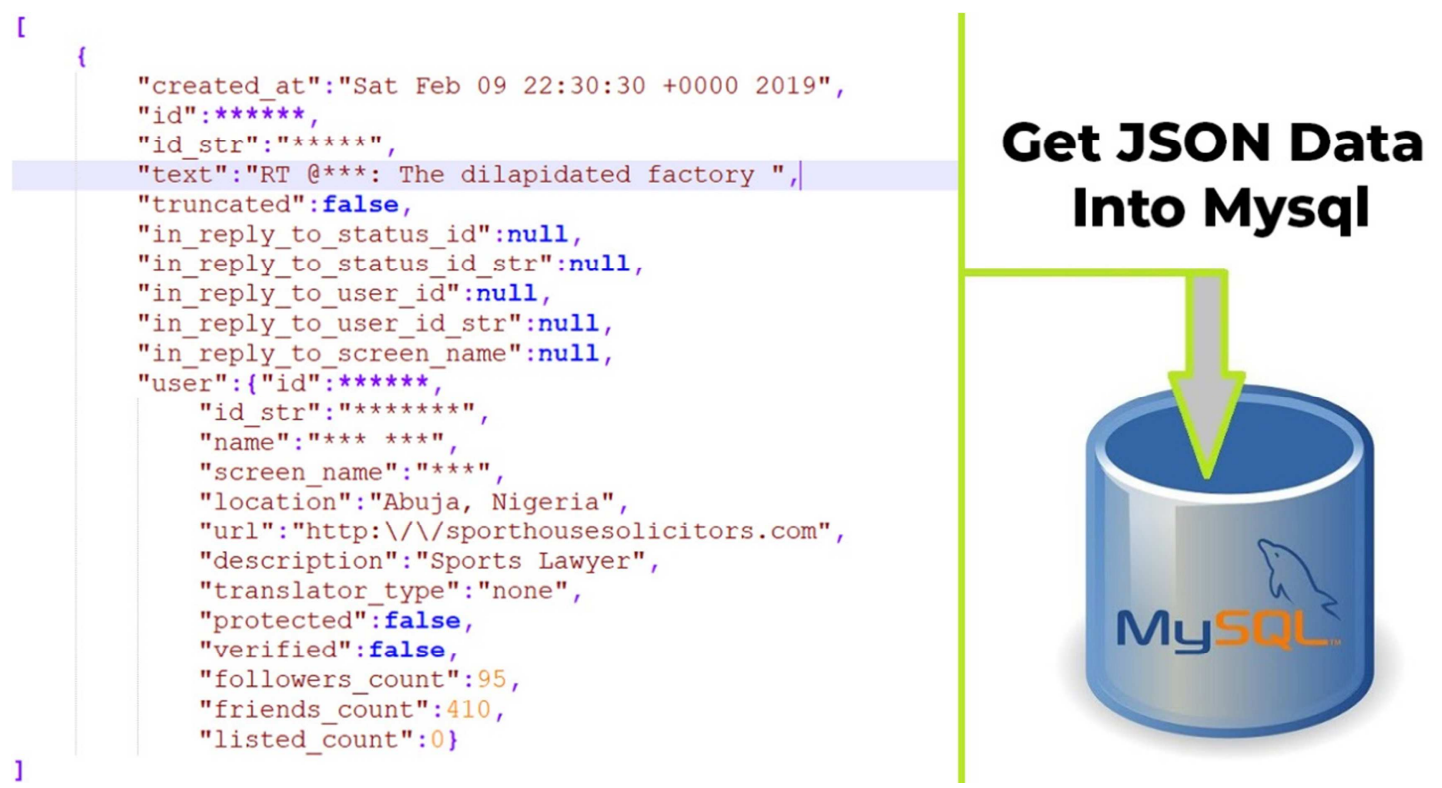

Figure 3. Storing JSON data into MySQL Database.

Firstly, we pooled all the JSON data from twitter into MySQL database using PHP web programming to enable us evaluate the sentiments and store them in a repository for

\begin{tabular}{|l|}
\hline Tweet 10 \\
\hline Tweet 9 \\
\hline Tweet 8 \\
\hline Tweet 7 \\
\hline Tweet 6 \\
\hline Tweet 5 \\
\hline Tweet 4 \\
\hline Tweet 3 \\
\hline Tweet 2 \\
\hline Tweet 1 \\
\hline
\end{tabular}

further analysis. All the data moved into the repository were then analysed using VADER to indicate the sentiments and also the candidate that the sentiment was directed at.

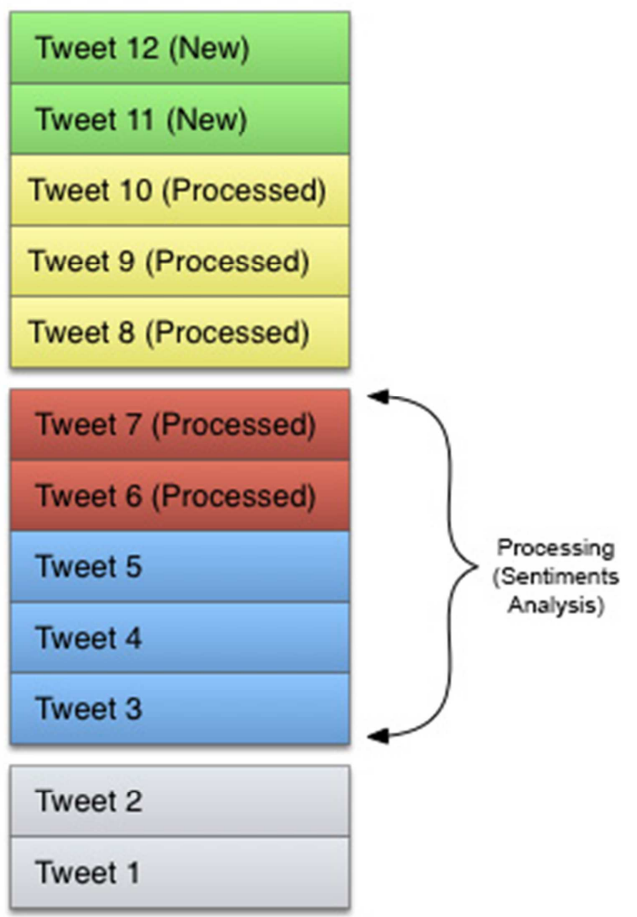

Figure 4. Processing each data.

When the sentiments have been captured, the data is stringified into JSON and parsed to Chart. js library (a pre-programmed system based off of JavaScript for plotting multi-dimensional graphs) to produce charts for viewership and demonstration. 


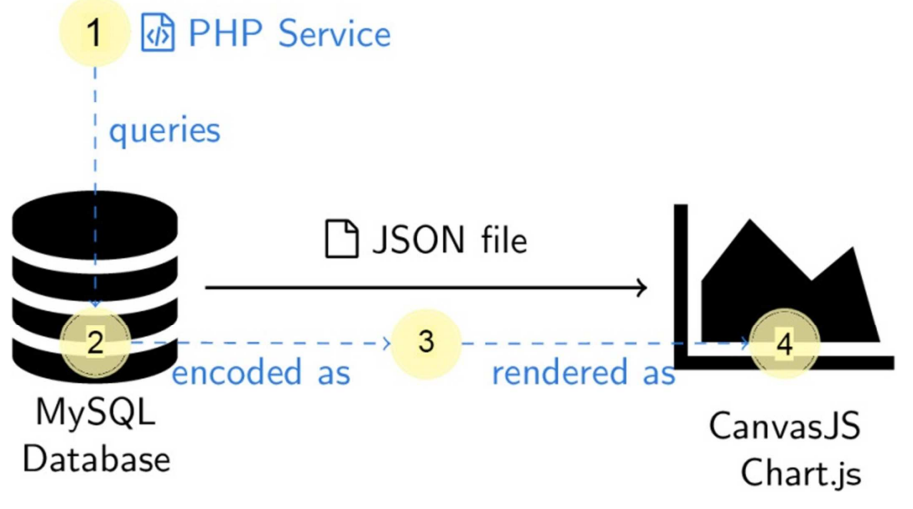

Figure 5. Process of parsing MySQL data into JSON and rendering with Chart. js.

\subsection{Plotting Sentiments Graph}

This was achieved using Chart.js library, HTML and CSS.

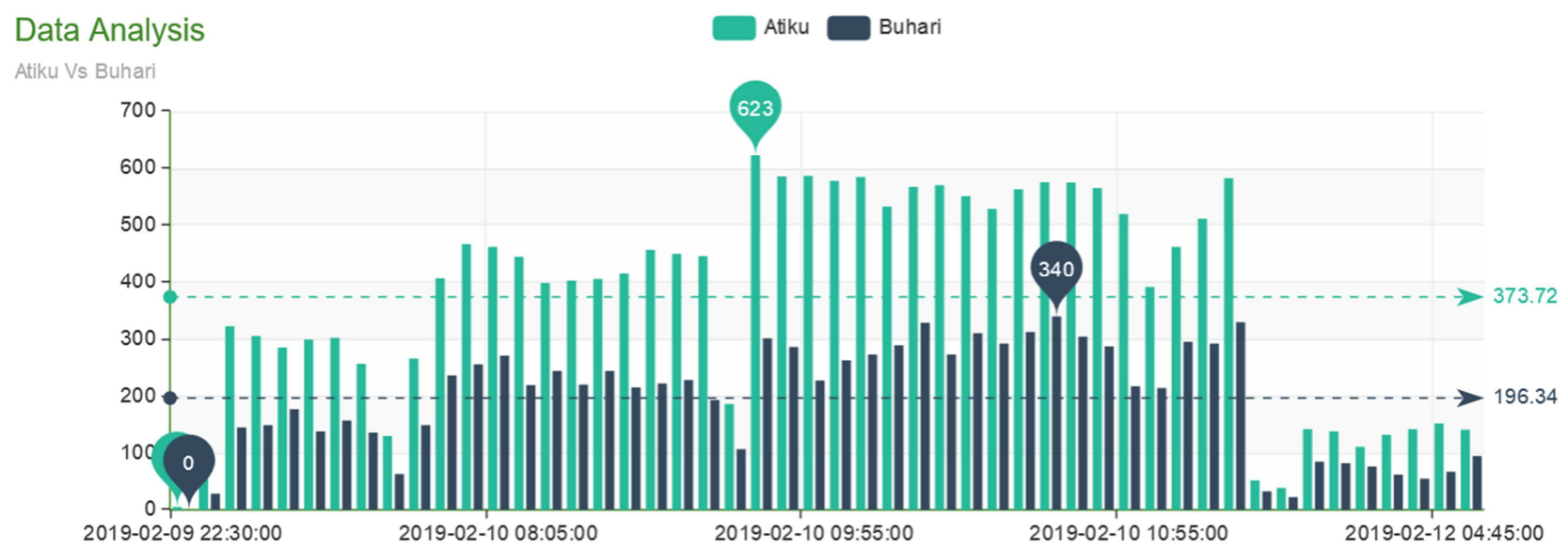

Figure 6. Sentiment mapping using Bar graph.

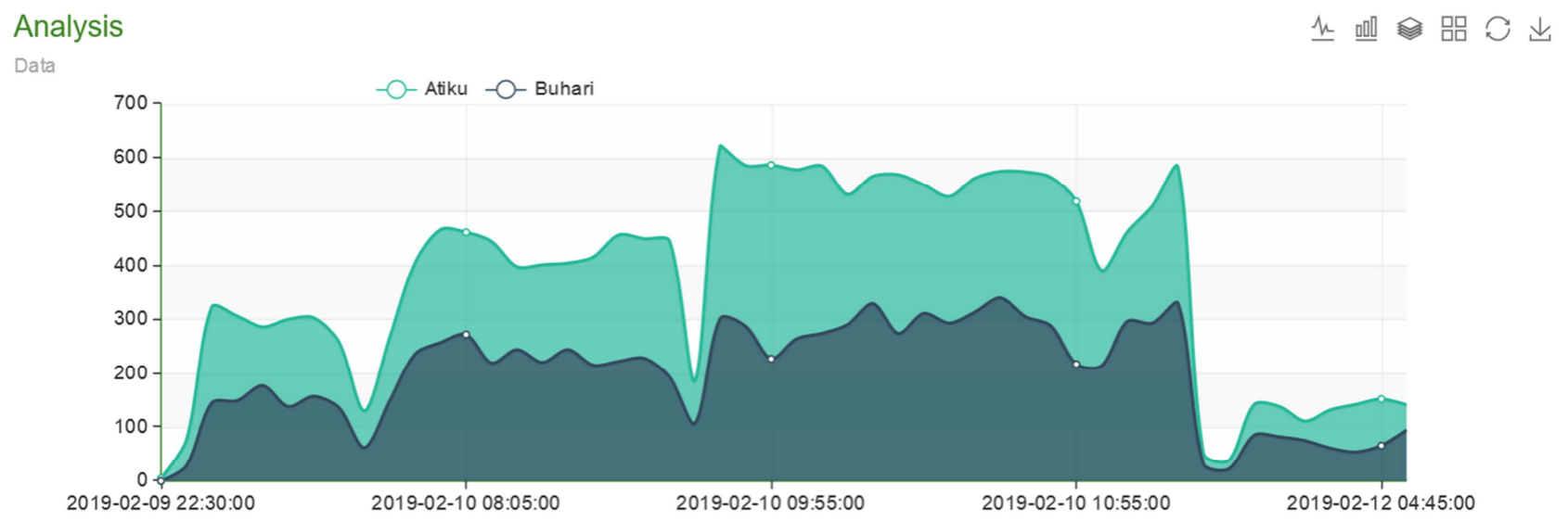

Figure 7. Sentiment mapping using stream/line graph.

\section{Conclusion}

The media is a great avenue to gauge public sentiments in order to ascertain the overall welfare of a people in a particular geographical location without barrier. From the introduction, the turnout of 2019 election voters in Nigeria decreased significantly in contrast to 2015 election and that could be attributed to security concerns, corruption, and indifference amongst the electorate. Notwithstanding the challenges, the election held. From the analysis, it's clear that the votes casted in major locations reflected the wishes of vast majority of Nigerians. Therefore, we can say that though the analysis wasn't meant to predict the winner of the 
election but to measure sentiments. This analysis depicts the wishes of the people and thus, we can however use this approach to make meaningful decision from a large myriad of sentiments.

\section{References}

[1] Emejulu A. O., Okpala I. U., Nwakanma I. C. (2019). Digital Language Mining Platform for Nigerian Languages (DLMP). International Journal on Data Science and Technology. Vol. 5, No. 1, 2019, pp. 1-7. doi: 10.11648/j.ijdst.20190501.11.

[2] SaharaReporters (2019) DATA: Nigeria's Presidential Election Records Lowest Voter Turnout in 20 Years Retrieved from http://saharareporters.com/2019/02/26/data-nigeriaspresidential-election-records-lowest-voter-turnout-20-years.

[3] Yiaga Africa (2019) Watching The Vote Preliminary Press Statement Retrieved from https://watchingthevote.org/yiagaafricas-watching-the-vote-preliminary-press-statement/.

[4] Beigi, G., Jalili, M., Alvari, H., \& Sukthankar, G. (2014). Leveraging community detection for accurate trust prediction.

[5] Carbonell, J. G. (1979). Subjective Understanding: Computer Models of Belief Systems (No. RR-150).

[6] Wilks, Y., \& Bien, J. (1983). Beliefs, points of view, and multiple environments. Cognitive Science, 7 (2), 95-119.

[7] Pak, A., \& Paroubek, P. (2010, May). Twitter as a corpus for sentiment analysis and opinion mining. In LREc (Vol. 10, No. 2010, pp. 1320-1326).

[8] Hutto, C. J., \& Gilbert, E. (2014, May). Vader: A parsimonious rule-based model for sentiment analysis of social media text. In Eighth international AAAI conference on weblogs and social media.

[9] Election Guide (2019). Federal Republic of Nigeria Retrieved from http://www.electionguide.org/countries/id/158/.

[10] Agatonovic-Kustrin S1, Beresford R. (2000). Basic concepts of artificial neural network (ANN) modeling and its application in pharmaceutical research. Retrieved from https://www.ncbi.nlm.nih.gov/pubmed/10815714.
[11] Khan, A., Baharudin, B., \& Lee, L. H. (2010). Khairullah khan, (2010). A Review of Machine Learning Algorithms for Text-Documents Classification, journal of advances in information technology, 1 (1).

[12] Bohanec, M., Moyle, S., \& Wettschereck, D. (2001). A software architecture for data pre-processing using data mining and decision support models.

[13] Beaugrande and Dressler (1992). Nigeria and the role of English language in the $21 \mathrm{st}$ century Retrieved from https://eujournal.org/index.php/esj/article/download/1153/116 9.

[14] Santesteban, M., Pickering, M. J., Laka, I., \& Branigan, H. P. (2015). Effects of case-marking and head position on language production? Evidence from an ergative OV language. Language, Cognition and Neuroscience, 30 (9), 1175-1186.

[15] Zhao, Z. A., \& Liu, H. (2011). Spectral feature selection for data mining. Chapman and Hall/CRC.

[16] Danladi, S. S. (2013). Language policy: Nigeria and the role of English language in the 21st century. European Scientific Journal, ESJ, 9 (17).

[17] Song, Y. Y., \& Ying, L. U. (2015). Decision tree methods: applications for classification and prediction. Shanghai archives of psychiatry, 27 (2), 130.

[18] Beigi, G., Hu, X., Maciejewski, R., \& Liu, H. (2016). An overview of sentiment analysis in social media and its applications in disaster relief. In Sentiment analysis and ontology engineering (pp. 313-340). Springer, Cham.

[19] Zafarani, R., Abbasi, M. A., \& Liu, H. (2014). Social media mining: an introduction. Cambridge University Press.

[20] Kumar, S., Morstatter, F., \& Liu, H. (2014). Twitter data analytics (pp. 1041-4347). New York: Springer.

[21] Holiday, R. (2013). Trust me, i'm lying: confessions of a media manipulator. Penguin. 